\title{
A pilot study of leakage and compartmentalization of the contrast agent Ablavar
}

\author{
Octavia Bane ${ }^{1,2^{*}}$, Daniel C Lee $^{3}$, Brandon Benefield ${ }^{3}$, Michael Markl ${ }^{1,2}$, James Carr ${ }^{1}$, Timothy J Carroll ${ }^{1,2}$ \\ From 16th Annual SCMR Scientific Sessions \\ San Francisco, CA, USA. 31 January - 3 February 2013
}

\section{Background}

We evaluate the compartmentalization of the blood pool agent Ablavar (Lantheus Medical Imaging) for the quantification of steady-state tissue blood volume.

\section{Methods}

Simulation study: In vitro studies have shown Ablavar to be $80-90 \%$ bound to albumin, with up to 10 fold relaxivity difference between bound and free fractions. We performed simulations to assess the effect of extravasation of the free fraction on signal. Vascular fraction measurements were simulated assuming slow two-compartment exchange for different contrast agent injection concentrations, binding fractions, bound and free relaxivity, and true vascular fractions.

Volunteer study: five healthy volunteers (4 males, average age 33) underwent T1 measurement pre and 2 minutes post administration of five injections of 0.006 $\mathrm{mmol} / \mathrm{kg}$ (a fifth of a single dose) Ablavar. Steady-state T1 was mapped using a cardiac gated Modified Look Locker Inversion Recovery (MOLLI) pulse sequence (slice thickness $8 \mathrm{~mm}$, FOV $300 \times 400 \mathrm{~mm}^{2}$, matrix 256 x 172, effective TI $100 \mathrm{~ms}$ ).
Image Processing: Maps of vascular fraction were calculated from signal difference maps, according to a slow water exchange model. Fv was measured in the myocardium, dome of the liver, and skeletal muscle visible on the short axis MOLLI images, and was corrected for Ablavar extravasation based on the leakage study.

The true $\mathrm{fv}$ and exchange rate of water protons was determined by chi square minimization between data and simulations of the effect of water exchange on $\mathrm{fv}$ according to the two compartment water exchange model presented by Donahue et al. (1996).

\section{Results}

We found that the effect of partial binding of Ablavar on the measurement of vascular fraction is less that $20 \%$. The true vascular fractions and exchange rates are summarized in Table 1. A comparison of the myocardium relaxation rate induced by administration of Ablavar in healthy volunteers imaged at $1.5 \mathrm{~T}$ and $3 \mathrm{~T}$, with other extracellular and intravascular contrast agents shows that Ablavar behaves like an extracellular contrast agent (Figure 1).

Table 1 Measurements of vascular fraction

\begin{tabular}{ccccc}
\hline & Measured fv (\%) & Measured exchange rate $(\mathrm{Hz})$ & Fv slow exchange (\%) Donahue et al. & Fv fast exchange Donahue et al. \\
\hline Myocardium & 25 & 41 & - & - \\
Liver & 45 & 3.7 & $41 \pm 6$ & $26 \pm 7$ \\
Muscle & 16 & 1 & $8 \pm 3$ & $15 \pm 1$ \\
\hline
\end{tabular}

Measurements of vascular fraction compared to those of Donahue et al. (1996) in the fast and slow limits of the water compartmentalization model.

${ }^{1}$ Radiology, Northwestern University, Chicago, IL, USA

Full list of author information is available at the end of the article

(C) 2013 Bane et al; licensee BioMed Central Ltd. This is an Open Access article distributed under the terms of the Creative Commons 


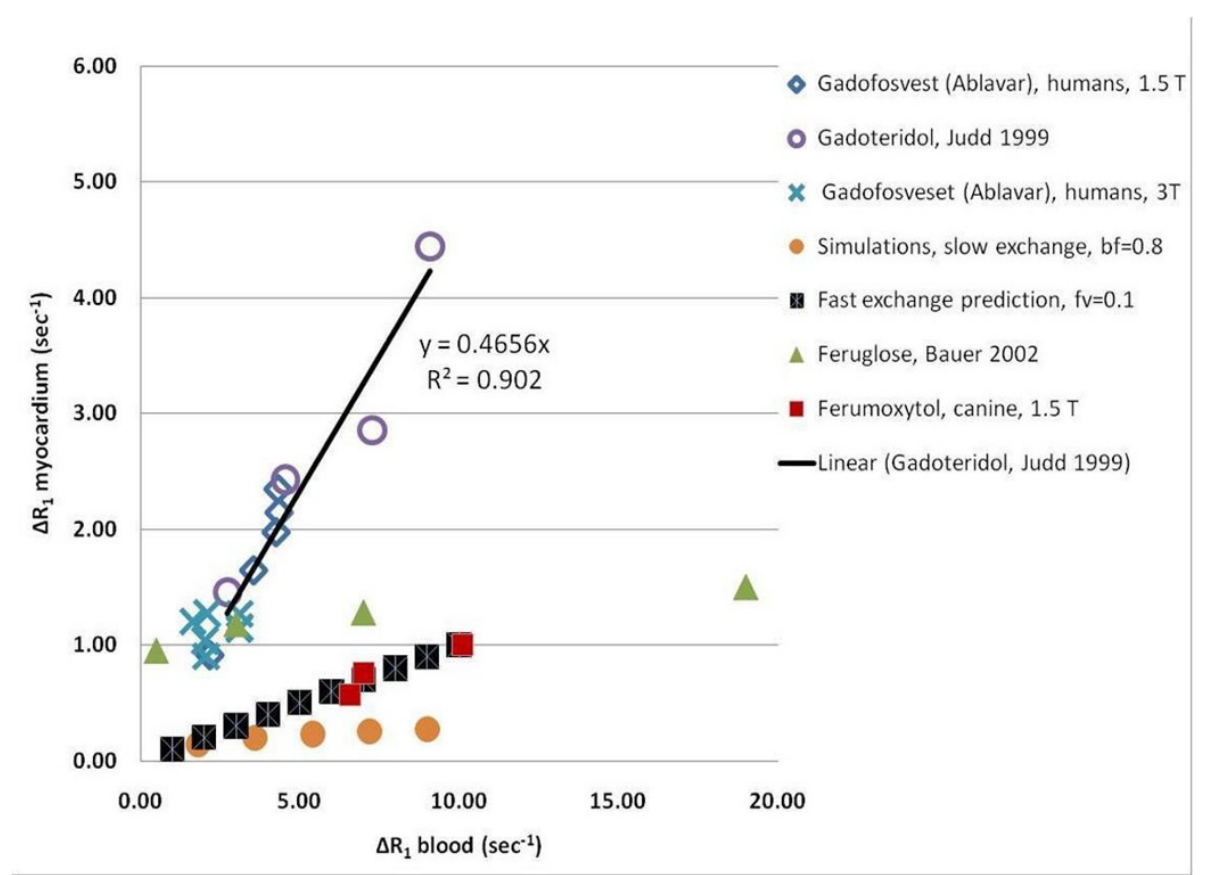

Figure 1 Myocardium longitudinal relaxation rates R1 as a function of blood longitudinal relaxation rates for Ablavar in healthy volunteers displays the same linear relationship as an extracellular agent. In comparison, intravascular USPIO agents feruglose and ferumoxytol display a non-linear trend. Ferumoxytol data is within the bounds predicted by the slow and fast exchange limits of the two compartment model.

\section{Conclusions}

The measured values of $\mathrm{fv}$ in liver and muscle agree with the Donahue model. Measured myocardial fv values over-estimate published values (9-12\%), and approach those of extracellular volume (25\%), which suggests the intravascular assumption may not be appropriate for Ablavar. The distribution of the volunteer data indicates that a three-compartment model, with slow exchange of Ablavar and water protons between the vascular and interstitial compartments, and fast water exchange between the interstitium and the cells is required to use Ablavar for quantification of blood volume.

\section{Funding}

R01 NHLBI HL088437.

Lantheus Medical Imaging provided the agent.

\section{Author details}

${ }^{1}$ Radiology, Northwestern University, Chicago, IL, USA. ${ }^{2}$ Biomedical Engineering, Northwestern University, Evanston, IL, USA. ${ }^{3}$ Feinberg Cardiovascular Institute, Northwestern University, Chicago, IL, USA.

Published: 30 January 2013
doi:10.1186/1532-429X-15-S1-E7

Cite this article as: Bane et al:: A pilot study of leakage and compartmentalization of the contrast agent Ablavar. Journal of Cardiovascular Magnetic Resonance 2013 15(Suppl 1):E7.

\section{Submit your next manuscript to BioMed Central} and take full advantage of:

- Convenient online submission

- Thorough peer review

- No space constraints or color figure charges

- Immediate publication on acceptance

- Inclusion in PubMed, CAS, Scopus and Google Scholar

- Research which is freely available for redistribution

Submit your manuscript at www.biomedcentral.com/submit 